\title{
Interacción entre el virus de la inmunodeficiencia humana y el virus GB tipo-C durante el estado de co-infección
}

\author{
Johanna C. Arroyave, Flor H. Pujol, María C. Navas y Fabián M. Cortés-Mancera
}

\section{Interaction between HIV-1 and GB virus type-C during coinfection status}

The human immunodeficiency virus (HIV) infection is one of the most important problems in public health. It is estimated that 33 million people are infected around the world. HIV and GBV-C share the same transmission route, being frequent the co-infection. Since both viruses replicate in CD4+ lymphocytes, recent studies have described an interaction. Decreasing of HIV viral load and higher CD4 counts have been observed in co-infected patients, leading a better clinical outcome. Nevertheless, some epidemiological studies have shown contradictory results. Additionally, in vitro models report inhibition of HIV by E1, E2, NS3 and NS5A GBV-C proteins, resulting in a decreasing of p24 antigen. This review summarizes the principal findings about co-infection and mechanisms that have been proposed for HIV-1 inhibition.

Key words: HIV-1; HGV; GBV-C; Co-infection; immunomodulation.

Palabras clave: VIH-1; VHG; GBV-C; Co-infección; inmunomodulación.

\section{Introducción}

$\mathrm{E}$ 1 virus GB tipo C (GBV-C), también llamado virus de la hepatitis $\mathrm{G}(\mathrm{VHG})$, fue descrito inicialmente en pacientes con hepatitis aguda de etiología desconocida (hepatitis no A, no B, no E). Este virus fue clasificado en la familia Flaviviridae, dentro de un grupo de virus relacionados (virus GB) ${ }^{1}$.

Deinhardt y cols., en 1967 realizaron la primera descripción del agente GB. Los investigadores, inocularon suero del tercer día de evolución de un paciente con hepatitis no A no B en monos Titi (Saguinus sp), demostrando el desarrollo de hepatitis por la elevación de enzimas hepáticas y alteración histológica del hígado en estos animales y en otros pases sucesivos de inoculación; el agente transmisible fue denominado agente GB (por las iniciales del paciente G Barker). Posteriormente, en 1995 se identificaron dos virus genéticamente relacionados, en muestras de suero y de tejido hepático de esos primates inoculados: el virus GB tipo A (GBV-A) y el virus GB tipo $\mathrm{B}$ (GBV-B); aunque sólo el segundo fue asociado con el desarrollo de hepatitis en primates. Ninguno de estos dos virus logró detectarse en muestras humanas. Estudios extendidos llevarían a la detección en humanos de un tercer virus con alta similaridad nucleotídica a los agentes GBV-A y GBV-B, por lo que fue denominado GBV-C ${ }^{1-3}$.

En años posteriores, algunos estudios serían realizados para tratar de establecer factores de riesgo en pacientes con enfermedad hepática, sin resultados concluyentes que permitan asociar al GBV-C con hepatopatía. Por el contrario, trabajos epidemiológicos y experimentales adelantados en la última década han vinculado al GBV$\mathrm{C}$ con la inhibición del virus de la inmunodeficiencia humana tipo 1 (VIH-1) en el contexto de co-infección, afectando favorablemente la evolución clínica y retrasando el progreso a SIDA (síndrome de inmunodeficiencia humana) $)^{4}$. En esta revisión se destacan los principales estudios clínicos acerca de la co-infección GBV-C/VIH y las evidencias in vitro que soportan el efecto inhibitorio sobre la replicación de VIH-1 mediado principalmente por las proteínas E1, E2, NS3 y NS5A del virus GB tipo $\mathrm{C}^{5}$.

\section{El virus GB tipo C}

El GBV-C presenta una amplia distribución mundial. Los principales factores de riesgo son la exposición a sangre, transfusión de hemoderivados contaminados y el contacto sexual; las transfusiones sanguíneas constituyen una forma de transmisión importante, puesto que en los bancos de sangre no es obligatoria la implementación de pruebas de tamizaje para el GBV-C ${ }^{1}$. Este virus está clasificado en la familia Flaviviridae, para el cual se ha propuesto recientemente el género Pegivirus, incluyendo el GBV-A y GBV-D; los cuales infectan primates no humanos y murciélagos frugívoros, respectivamente ${ }^{1,5}$. El GBV-C posee un genoma de ARN de cadena sencilla con polaridad positiva, de aproximadamente $9,4 \mathrm{~kb}$, filogenéticamente relacionado con el virus de la hepatitis $\mathrm{C}$ (VHC), con una organización y función similar en sus genes (similaridad de $29 \%$ en su región codificante). Como se muestra en la Figura 1A, el genoma del GBV-C posee un sólo marco abierto de lectura (ORF; de las siglas

\author{
Instituto Tecnológico \\ Metropolitano, Medellín. \\ Antioquia, Colombia. \\ Facultad de Ciencias Exactas y \\ Aplicadas. Programa Ing. Biomédica \\ Grupo de Investigación e Innovación \\ Biomédica Gl²B (JCA, FMCM). \\ Universidad de Antioquia, \\ Medellín, Colombia. \\ Grupo de Gastrohepatología. \\ Sede de Investigación Universitaria \\ (MCN). \\ Instituto Venezolano de \\ Investigaciones Científicas, \\ Caracas, Venezuela. \\ Laboratorio de Virología Molecular \\ (FHP).
}

Los autores declaran no tener ningún conflicto de interés.

Financiamiento: Instituto Tecnológico Metropolitano, Dirección de Investigaciones. Código del proyecto: P10243

Recibido: 21 de agosto de 2012 Aceptado: 16 de noviembre de 2012

Correspondencia a: Fabián M Cortés Mancera fabiancortes@itm.edu.co 


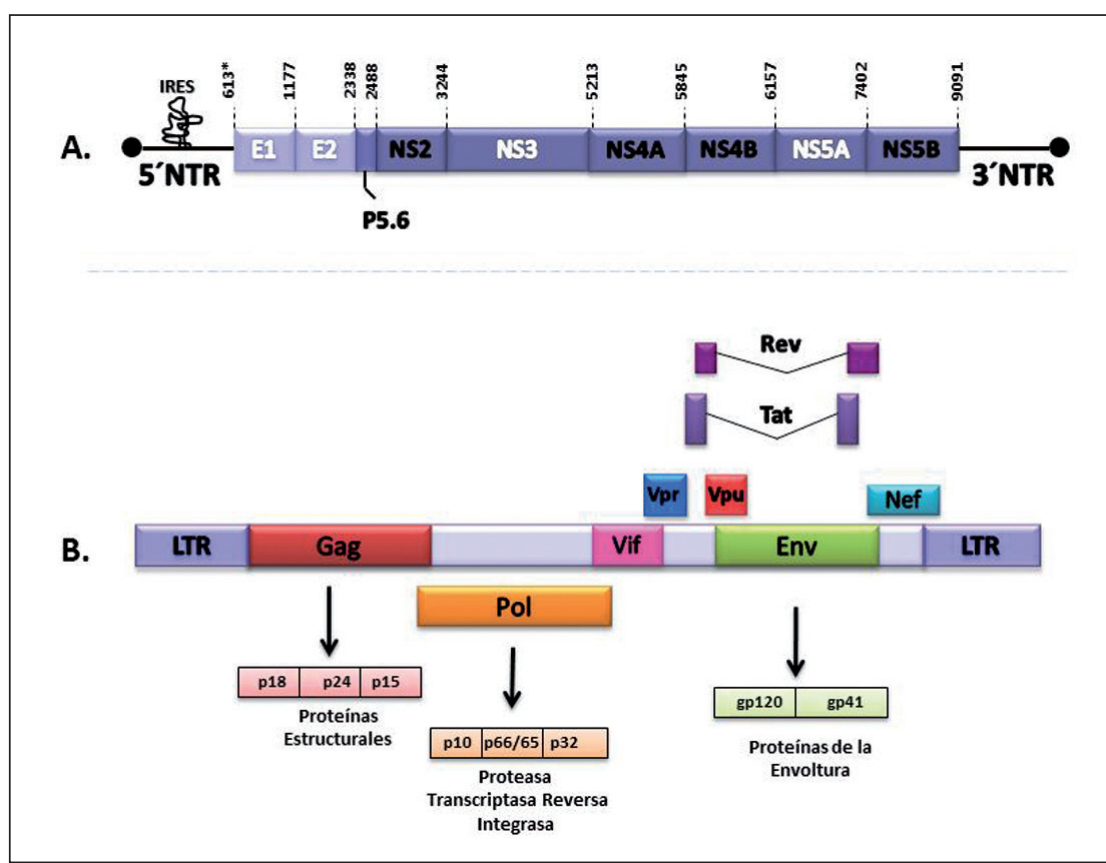

Figura 1. Organización genómica del GBV-C y el VIH-1. Esquema representativo de la estructura de los genomas virales. (A) Se muestra el ARN de 9,3 Kb del GBV-C, junto con sus regiones no traducidas (NTR) en los extremos 5 y 3', flanqueando la región codificante (ORF). En el 5'NTR se destaca la estructura secundaria IRES (sitio interno de entrada al ribosoma), la cual media la traducción Cap-independiente de la poliproteína. *Los números verticales indican la posición nucleotídica de los segmentos codificantes, según la nomenclatura descrita por Worobey y Holmes en 2001. Una poliproteína de aproximadamente 3.000 aminoácidos es sintetizada a partir del ARN genómico, la cual incluye las glicoproteínas E1-E2 (proteínas estructurales), p5.6 y NS2-NS5B (proteínas no estructurales); las regiones genómicas escritas en blanco (E1, E2, NS3 y NS5A) corresponden a los productos génicos con reporte en la literatura científica de actividad inhibitoria in vitro contra el VIH1. (B) Estructura genómica del VIH-1; el esquema resalta el ADN proviral, flanqueado por regiones repetitivas extensas, denominadas LTR. A partir de este se transcriben los ARNm que codifican para las proteínas estructurales (Gag), la envoltura (Env) y las enzimas con actividad transcriptasa reversa, proteasa e integrasa (Pol); también se destacan las regiones genómicas que codifican paralas proteínas accesorias (Vif, Vpr, Vpu, Nef, Tat y Rev).

en inglés open reading frame) flanqueado por regiones no codificantes en sus extremos 5' y 3' (5'NTR y 3'NTR, respectivamente); el ORF codifica para una poliproteína de aproximadamente 3.000 aminoácidos ${ }^{2,5}$. Como en el caso del VHC, el extremo 5'NTR del genoma del GBV$\mathrm{C}$ presenta una estructura secundaria (IRES) que sirve para el reclutamiento de las subunidades ribosomales y factores de la traducción, mediando el inicio de la síntesis de la poliproteína; en contraste no presenta poliA o poli-U en el extremo $3^{\prime} \mathrm{NTR}^{2}$. Una vez traducida la poliproteína, ésta es procesada proteolíticamente en nueve proteínas: dos proteínas estructurales correspondientes a las glicoproteínas E1 y E2 (E1/2) que hacen parte de la envoltura viral, y siete no estructurales (p5.6, NS2, NS3, NS4a, NS4b, NS5a y NS5b); entre éstas, se destaca NS3 con actividad helicasa y serina-proteasa, NS5b con actividad ARN polimerasa dependiente de ARN y una proteína de 5,6 $\mathrm{kDa}(\mathrm{p} 5,6)$ recientemente caracterizada, la cual presenta una función similar a la viroporina $\mathrm{p} 7$ de $\mathrm{VHC}^{1,5}$. Aunque se han realizado múltiples estudios sobre el genoma del GBV-C, aún no ha sido identificada la secuencia que codifica para la proteína de la subunidad de la cápside viral; se han propuesto ORFs alternativos o intermediarios replicativos como posible estrategia viral para la síntesis de esta proteína, como también la utilización de proteínas celulares por parte de GBV-C para formar su nucleocápside 5 . Según lo reportado para VHC, y teniendo en cuenta las secuencias señal, es probable que la poliproteína sea procesada inicialmente por proteasas celulares, dando lugar a E1, E2 y p5.6, siendo la serinaproteasa viral NS3, en complejo y NS4A (NS3/4A), quien complementa el procesamiento para dar lugar a NS4A, NS4B, NS5A y NS5B $\mathrm{B}^{1,2}$.

Según el análisis de secuencias, es considerado que el GBV-C tuvo su origen en el continente Africano'. Seis genotipos han sido descritos, designados con números arábigos del 1 al 6 (Figura 2), presentando una divergencia de hasta $14 \%$, y una distribución geográfica específica. Recientemente, fue propuesto un nuevo genotipo con circulación en China (designado como genotipo 7). Las regiones más utilizadas para los análisis de genotipificación incluyen la región 5 'NTR y la región genómica correspondiente a la glicoproteína E2 $2^{1,5}$.

$\mathrm{El}$ virus GBV-C es un agente que muestra una cercana asociación evolutiva con su hospedero, evidenciada en su amplia prevalencia en poblaciones humanas y su aparente no patogenicidad, consistente además con un largo proceso de interacción. Evidencia adicional es encontrada al analizar la distribución geográfica de genotipos ${ }^{1}$.

El genotipo 1, subtipos a y b (1a y $1 \mathrm{~b}$ ) se encuentra en el este de África, el genotipo 2 (2a y 2b) se distribuye principalmente en Norte América y en Europa. Los genotipos 3 y 4, se han encontrado en Asia y en el Sureste de Asia, circulando las cepas del genotipo 4 específicamente en Myanmar y Vietnam; el genotipo 5 se ha descrito recientemente en Sur África ${ }^{1}$. El genotipo 6 propuesto por Muerhoff y cols., se identificó en individuos de Indonesias.

En América Latina existen pocos estudios de caracterización genotípica del GBV-C, aunque se ha identificado circulación de los genotipos 1, 2 y 3 . El genotipo 1 ha sido determinado en Venezuela y Brasil; el genotipo 2 en Venezuela, Brasil, Argentina y Bolivia; y el genotipo 3 en Venezuela, Brasil, Argentina, Bolivia y Nicaragua ${ }^{5,6}$. Por su parte, en Venezuela se han reportado tanto en población general como amerindia alta circulación del genotipo $3^{5}$. De manera interesante, la alta frecuencia del genotipo 3 del GBV-C en poblaciones nativas de Latinoamérica es concordante con la hipótesis que sugiere que los primeros pobladores del continente americano son originarios del Asia $^{5,6}$.

Hasta ahora sólo han sido publicados dos estudios de 


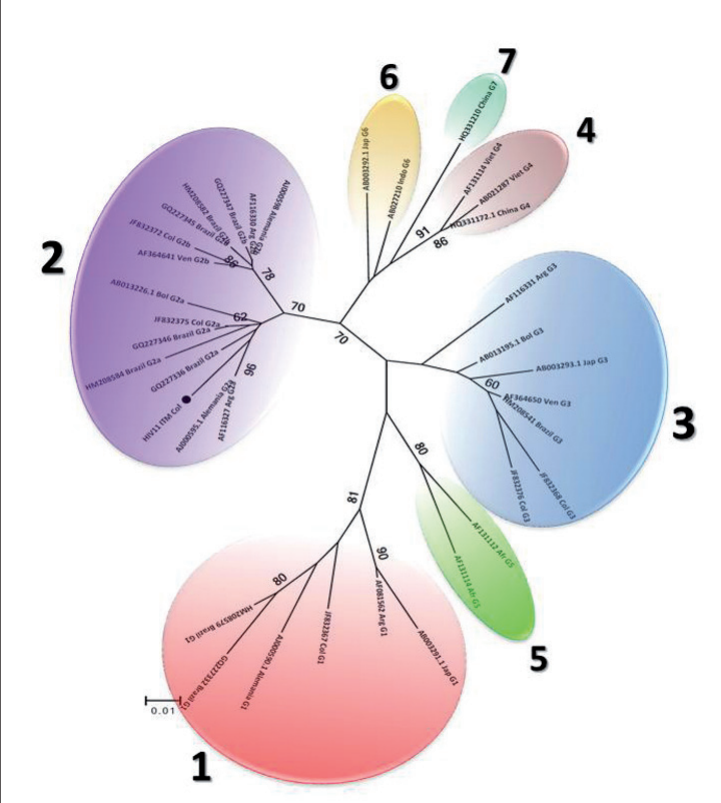

Figura 2. Diversidad genética del virus GB-C. Árbol sin raíz construido con secuencias 5'UTR de prototipos del GBV-C disponibles en GenBank, utilizando el método neighbor-joining y el modelo $\mathrm{K} 2+\mathrm{G}$ en el programa MEGA. Los números localizados en las ramas internas del árbol representan los valores de bootstrap (1.000 repeticiones). Las secuencias se agruparon en siete cladas, correspondientes al número genotipos descritos hasta la fecha en la literatura científica. En el nombre de las secuencias se describe el código de acceso GenBank, el país de origen de la secuencia y el genotipo al que pertenece. La secuencia resaltada con el circulo sólido perteneciente al genotipo $2 a$ (HIV1 1 ITMCol), corresponde a un aislado colombiano caracterizado en un estudio en donantes de sangre infectados por el VIH.

genotipificación del GBV-C en población colombiana. En 1998 se publicó un trabajo que incluyó muestras de tres grupos étnicos Wayuu, Kamsa e Inga, identificando al genotipo 3 como el de mayor prevalencia ${ }^{5}$. Otro estudio publicado en 2011, incluyó donantes de sangre de la ciudad de Bogotá con seropositividad para el virus de la hepatitis B (VHB) y/o virus de la hepatitis C (VHC). En la población de donantes se reportaron los genotipos 1, 2a, 2b y 3 del GBV-C, figurando el genotipo 2a como el más frecuente; en este mismo trabajo adicionalmente se estudió una población nativa del Amazonas, en la cual el único genotipo detectado fue el genotipo $3^{5}$. Resultados preliminares de un estudio que está siendo desarrollado por nuestro grupo, en el cual se incluyeron donantes de sangre colombianos infectados por el VIH, demuestran la presencia de los genotipos 2 y 3 , observándose una predominancia del genotipo 2a en la población analizada (Arroyave J y cols; dato no publicado); en la Figura 2 se muestra el agrupamiento de uno de los aislados secuenciados.
Como ya se mencionó, la transmisión del GBV-C se da principalmente vía parenteral ${ }^{1}$. Por esta razón es frecuente la co-infección con otros virus como VHB, VHC, y particularmente con VIH.

El GBV-C tiene la capacidad de generar una infección persistente, sin intermediarios replicativos de ADN conocidos. El ARN del GBV-C ha sido detectado en diferentes células y tejidos, tales como linfocitos de sangre periférica, monocitos, células endoteliales e hígado. Se ha demostrado que la mayoría de las personas inmunocompetentes que se infectan (65-70\%), desarrollan anticuerpos neutralizantes contra la glicoproteína E2 (Anti-E2), llevando al aclaramiento viral, en promedio, antes de dos años. En contraste, los individuos que desarrollan una infección persistente, presentan detección del ARN viral en suero por largos periodos de tiempo y ausencia de anticuerpos anti-E2. ${ }^{7} \mathrm{El}$ ARN viral constituye un marcador de infección que puede ser analizado mediante RPC-TR, usando partidores dirigidos a las regiones conservadas $5^{\prime}$ NTR, NS3 y NS5 ${ }^{8}$. Por su parte, la detección de los anticuerpos contra la glicoproteína E2 (anti-E2) mediante ELISA, revelan la existencia de infección pasada y sólo en un pequeño porcentaje $(<5 \%)$ se ha detectado la presencia simultánea de anticuerpos y de ARN viral ${ }^{9}$. A la fecha no existe una prueba comercial para el diagnóstico de esta infección. Según estos marcadores, las mayores prevalencias se observan en grupos en riesgo de infección tales como los politransfundidos, los hemodializados y los usuarios de drogas de abuso ${ }^{1,5}$. A nivel global, África y Latinoamérica presentan una alta prevalencia de infección por el GBV-C. En América del Sur, Brasil muestra el mayor número de estudios realizados, seguido por Argentina y Venezuela; en éstos, el marcador de infección más frecuentemente analizado corresponde a la detección del genoma del GBV-C por RPC-TR. Brasil, Argentina y Bolivia reportan frecuencias entre 5,5 y 14,6\%, describiendo un patrón de prevalencia moderada-alta ${ }^{5}$. Como ya se mencionó, en uno de lo estudios realizados en Colombia, se incluyeron muestras, tanto de población general, como de individuos pertenecientes a grupos indígenas con asentamiento en el suroccidente y norte del país; todos los grupos de individuos incluidos en este estudio presentaban una mayor proporción de mujeres que de hombres, y la generalidad no presentó alternaciones de los niveles de alanina amino-transferasas (ALT). Según la prueba molecular (RPC-TR), se obtuvo un valor promedio de detección del 6,1\% para las poblaciones indígenas, con un rango entre 5,6 y 6,7\%. En contraste, en población general se encontró una prevalencia de infección por el GBV-C de sólo $1,5 \%$, la frecuencia más baja encontrada en un país latinoamericano, ${ }^{5} \sin$ embargo, se debe tener en cuenta que este dato corresponde a un estudio realizado en 1998, y que tan sólo 67 individuos fueron incluidos en el grupo de población analizado, sin especificar la procedencia. En 
cuanto al estudio realizado por Alvarado-Mora y cols. en 2011, la tendencia fue similar, reportando la presencia del genoma del GBV-C entre 3,2 y 5,06\% de las muestras de población general infectada por virus hepatotrópicos, y de $7,7 \%$ en indígenas de las etnias ticuna y yaua, asentadas en el Amazonas 5 .

Aunque se considera a este agente como un virus no relacionado a enfermedad en humanos, algunos autores sugieren que GBV-C estaría involucrado con hepatopatía, ya que su genoma ha sido identificado en muestras de pacientes con enfermedad hepática crónica y hepatitis aguda no A-no $\mathrm{E}^{1}$.

En pacientes infectados con el GBV-C, los parámetros bioquímicos pueden ser normales hasta en $75 \%$ de los casos, con ausencia de cambios histológicos de importancia. Cuando se evalúa la presencia de ARN en suero y en tejido hepático, se encuentran mayores niveles de genoma viral en suero que en hígado, y hasta en un tercio de los pacientes con viremia, no se logra demostrar la presencia del virus en ese tejido ${ }^{1,10}$.

El GBV-C es un virus linfotrópico según se ha demostrado en diversos trabajos. La presencia de ARN del GBV-C se ha detectado en mononucleares de sangre periférica (PBMCs; del inglés Peripheral Blood Mononuclear Cells) de pacientes infectados, y también en las diferentes subpoblaciones de PBMCs, tales como linfocitos $\mathrm{T}$ (CD4+ y CD8+), linfocitos B y en menor proporción en monocitos. Adicionalmente PBMCs, y específicamente los linfocitos T CD4+ y CD8+, así como los linfocitos B CD19+, soportan la replicación in vitro del GBV-C; sin embargo, similar a lo observado en el VHC la replicación en condiciones controladas de cultivo celular es ineficiente y sólo algunas de las variantes del GBV-C presentes en suero/plasma son capaces de infectar y replicarse en condiciones in vitro en $\mathrm{PBMCs}{ }^{11}$.

Por otra parte, el tropismo por los hepatocitos no ha sido claramente evidenciado, especialmente porque a la fecha no se ha demostrado la presencia de ARN antigenómico viral en estas células. En contraste, genoma y antigenoma se ha detectado en bazo, médula ósea y PBMCs, indicando que el virus se replica en células de origen hematopoyético. Hallazgos adicionales indican la existencia de replicación extrahepática en la infección por el GBV-C, como la observación de más altas concentraciones de ARN viral en plasma que en tejido hepático ${ }^{11}$. Por otro lado, se ha planteado que la replicación del GBV-C en células del endotelio vascular podría explicar la detección del virus en muestras de hígado; aunque no exista replicación en el hepatocito ${ }^{7}$. En este sentido Fogeda y cols., describieron la existencia de variantes del virus con diferente tropismo, al analizar la región 5'NTR del GBV-C amplificado a partir de muestras pareadas de suero, PBMCs y tejido hepático, de dos pacientes con infección crónica por el GBV-C y co-infectados con el
VHC. En este estudio se detectó ARN del GBV-C en los tres tipos de muestras analizadas, encontrando la presencia de variantes o cuasi-especies del virus en PBMCs y en suero, las cuales eran genéticamente diferentes a las encontradas en tejido hepático. Lo anterior sugiere una compartimentalización del GBV-C, y la existencia de variantes del GBV-C con diferente tropismo por los linfocitos y células presentes en el hígado ${ }^{12}$.

Aunque a la fecha el GBV-C no es considerado un patógeno en humanos, recientemente un estudio de casos y controles realizado en Canadá reportó una asociación con linfoma no Hodgkin (NHL), encontrando mayor riesgo de desarrollar NHL en pacientes virémicos para el GBV-C comparados con los controles negativos para el ARN del virus ${ }^{13}$; por lo que, se hace necesario realizar más estudios que demuestren el papel del GBV-C como factor de riesgo en el desarrollo de este cáncer y de otras patologías relacionadas.

\section{Virus de la inmunodeficiencia humana}

La infección por el VIH constituye uno de los mayores problemas de salud pública en el mundo, debido a que este virus es el agente causal del SIDA, síndrome que se ha asociado con 25 millones de muertes en el mundo aproximadamente; a la fecha se estima cerca de 33 millones de individuos infectados ${ }^{14}$.

El VIH es un lentivirus perteneciente a la familia Retroviridae; su genoma constituye dos copias de ARN lineal de polaridad positiva, de aproximadamente $9,8 \mathrm{~kb}$. Como en todos los retrovirus, una enzima transcriptasa reversa interviene en su ciclo replicativo, la cual genera el ADN complementario del genoma viral, flanqueado por secuencias repetitivas (LTR; del inglés long terminal repeats), las cuales permiten su integración al genoma de la célula hospedera, como también la regulación transcripcional del provirus. A partir del provirus integrado se transcriben los diferentes ARNs mensajeros que codifican nueve proteínas; tres precursoras (Gag, Pol, Env), dos proteínas reguladoras (Tat, Rev) y cuatro proteínas accesorias (Nef, Vif, Vpu, Vpr) (Figura 1B) ${ }^{15}$. Las proteínas de la envoltura gp120 y gp41 son producidas a partir de Env. Las proteínas de la matriz, la cápside, nucleocápside y p6 son procesadas a partir de Gag, mientras que la transcriptasa reversa, la integrasa y la proteasa viral lo hacen a partir de Pol; las proteínas reguladoras, tienen función en la replicación viral y también tienen efecto en la célula hospedera ${ }^{16}$.

El VIH-1 utiliza la glicoproteína gp120 para la interacción con el receptor CD4, presente en células como linfocitos $\mathrm{T}$, linfocitos primarios y macrófagos. Para la penetración de la partícula viral se necesita la interacción con moléculas co-receptoras presentes en la membrana 
de las células blanco, principalmente CXCR4 y CCR5 (receptores de quimioquinas) ${ }^{17}$. El co-receptor CXCR4 está presente principalmente en linfocitos del linaje $\mathrm{T}$ y en linfocitos primarios; el ligando natural de CXCR4 es la quimioquina SDF-1 (del inglés, stromal cell-derived factor-1alpha). De otra parte, el co-receptor CCR5 se expresa principalmente en monocitos y también en linfocitos primarios. Esta molécula tiene la capacidad de unirse a diferentes quimioquinas como RANTES (del inglés, regulated on activation normal $T$ cell expressed and secreted), MIP-1 $\alpha$ y MIP-1 $\beta$ (del inglés, macrophage inflamatory protein 1alpha, 1beta $)^{18}$. Según la capacidad de las diferentes cepas de VIH-1 para interactuar con estos co-receptores, se han denominado X4 las cepas del virus que utilizan el co-receptor CXCR4; éstas se replican principalmente en poblaciones de linfocitos y aparecen en los estadíos tardíos de la infección, y se asocian con el declive del recuento de las células T CD4+. En contraste, se han denominado R5 las cepas del virus que utilizan el co-receptor CCR5, las cuales se replican principalmente en macrófagos. Se ha descrito que los virus R5 son de importancia en las etapas tempranas de la infección y en la transmisión; sin embargo estas se pueden detectar en todos los estadíos de la infección. Adicionalmente, se ha reportado en la literatura científica la existencia de cepas duales, con capacidad de usar ambos co-receptores, denominadas cepas X4R5 ${ }^{19}$.

Una vez en el citosol, el ARN viral es desencapsidado y utilizado como molde para la generación de una copia complementaria de ADN de doble cadena (dscADN), proceso que es mediado por la transcriptasa reversa viral y el tARNlys 3 celular (ARN de transferencia). El dscADN lineal forma el complejo de preintegración (PIC), conformado por las proteínas virales: transcriptasa reversa, proteína de matriz, integrasa y $\mathrm{Vpr}$; junto con algunas proteínas celulares. El PIC es translocado al núcleo mediante la interacción con los poros nucleares, donde ocurre la integración del dscADN lineal al genoma de la célula hospedera, originándose la forma proviral (Figura 1B). En el provirus, el LTR-5' actúa como un promotor y el LTR-3' como un sitio de poliadenilación y terminación de la transcripción (similar a un gen celular) para regular la transcripción de los diferentes ARNs mensajeros, los cuales darán origen a las proteínas del virus y al ARN genómico para producir las nuevas partículas virales ${ }^{20}$.

La infección por VIH se presenta principalmente con progresión lenta y se caracteriza por largos periodos de tiempo sin manifestaciones clínicas. La patogénesis de la infección por VIH puede dividirse en dos etapas; una fase aguda, que se presenta con una disminución significativa de linfocitos T CD4+ en mucosas, principalmente a nivel del tejido linfoide asociado a tracto digestivo (GALT, del inglés gut-associated lymphoid tissue); y una fase crónica caracterizada por una activación inmune con una alta producción de citoquinas pro-inflamatorias. Durante esta fase crónica, el recuento de linfocitos T CD4+ en sangre periférica declina progresivamente, lo cual puede ser parcialmente reversible por la terapia anti-retroviral; sin embargo este fenómeno se exacerba durante la fase de aparición del SIDA ${ }^{19}$.

La disminución de los linfocitos T CD4+ en los individuos infectados con VIH es resultado de diversos mecanismos directos e indirectos; como la alteración de la producción de linfocitos $\mathrm{T}$ de novo en el timo, inducción de sincicios, alteración de la permeabilidad de la membrana, disfunción mitocondrial, y destrucción de las células infectadas mediada por los linfocitos T CD8+ durante la activación inmune. La determinación de la carga viral y del recuento de CD4 son dos marcadores utilizados para evaluar la evolución del paciente infectado por VIH, junto con los parámetros clínicos ${ }^{19,20}$.

Los diferentes aislados del VIH-1 han sido clasificados en tres grupos $\mathrm{M}, \mathrm{O}$ y N ; destacándose con mayor frecuencia los aislados del grupo $\mathrm{M}$ por ser los causantes de la mayoría de casos a nivel global. Dentro de M, se han identificado al menos 12 subtipos (A-K), los cuales corresponden a las diferentes cladas equidistantes según análisis filogenéticos basados en las diferentes regiones genómicas (Gag, Pol y Env), o en secuencias del genoma completo; adicionalmente también se han reportado diferentes formas recombinantes. Los subtipos más frecuentes en el mundo son A, B y C. En Latinoamérica, se han identificado como predominantes el subtipo B y la forma recombinante $\mathrm{BF}^{21}$.

\section{Co-infección GBV-C/VIH}

Gracias a diversos trabajos se ha observado que la frecuencia de co-infección GBV-C/VIH es característicamente alta; las tasas encontradas varían entre $14 \mathrm{y}$ $45 \%$, siendo más altas en hombres que tienen sexo con hombres y usuarios de drogas intravenosas. Los reportes de co-infección varían dependiendo de la región y de la población ${ }^{4}$. En la Tabla 1 se resumen las características y principales hallazgos de diferentes estudios epidemiológicos en los que se ha analizado el efecto de la co-infección GBV-C/VIH; en el este de África, estudios en cohortes de pacientes infectados por el VIH sin terapia anti-retroviral, revelan tasas de co-infección de $25,7 \%$ en asintomáticos, y $10.9 \%$ en pacientes sintomáticos ${ }^{22}$. Una frecuencia similar se encontró en un estudio de corte transversal realizado en 106 pacientes iraníes, de los cuales 12 (11,3\%) presentaron infección simultanea por el GBV-C y aunque no hubo diferencia estadísticamente significativa, en este grupo de co-infectados hubo menos individuos que necesitaron terapia HAART ( 25 vs 43,6\%); en este trabajo se determinó además que todos los aislados pertenecían al GBV-C genotipo $2 \mathrm{a}^{23}$. Aunque existen pocos estudios 
Tabla 1. Descripción de los principales estudios epidemiológicos en los que se ha evaluado la interacción GBV-C/VIH

\begin{tabular}{|c|c|c|c|c|c|}
\hline Tipo de estudio & Grupo de estudio & $\mathrm{n}^{*}$ & Hallazgo & País & Autores \\
\hline Cohorte & Gestantes & 260 & $\begin{array}{l}\text { No se observa asociación entre el estado de co-infección y los niveles de } \\
\text { CD4 o carga viral del VIH }\end{array}$ & Gambia & Kaye y cols 2005 \\
\hline $\begin{array}{l}\text { Descriptivo/ } \\
\text { prospectivo }\end{array}$ & HAART** & 175 & $\begin{array}{l}\text { La viremia de VIH presenta valores más bajos durante la terapia anti-viral } \\
\text { cuando el paciente esta co-infectado con el GBV-C }\end{array}$ & Brasil & Souza y cols 2006 \\
\hline Meta-análisis & Pacientes & $2.206^{* * *}$ & $\begin{array}{l}\text { No hay asociación concluyente entre la presencia del GBV-C y la sobrevida } \\
\text { del paciente cuando se da la co-infección durante los dos años siguientes } \\
\text { a la seropositividad para VIH, pero sí cuando hay co-infección más tardía- } \\
\text { mente ( } \geq 2 \text { años) }\end{array}$ & $\begin{array}{l}\text { EUA, Ps. Bj, } \\
\text { Jap, Sue, Fra }\end{array}$ & Zhang y cols 2006 \\
\hline Cohorte & Heterosexuales & 272 & $\begin{array}{l}\text { Infección activa por el GBV-C mejora la tasa de sobrevida en personas } \\
\text { infectadas por el VIH }\end{array}$ & Uganda & Yirrell y cols 2007 \\
\hline $\begin{array}{l}\text { Descriptivo/ } \\
\text { prospectivo }\end{array}$ & HAART** & 373 & $\begin{array}{l}\text { La infección persistente por GBV-C no confiere beneficios durante la HAART } \\
\text { al corto plazo }\end{array}$ & Taiwán & Sheng y cols 2007 \\
\hline Cohorte & Binomio madre/hijo & 1.364 & $\begin{array}{l}\text { Neonatos que adquieren el GBV-C presentan menor riesgo de transmisión } \\
\text { perinatal del VIH }\end{array}$ & Tailandia & Supapol y cols 2008 \\
\hline Cohorte & Hombres homosexuales & 233 & $\begin{array}{l}\text { Asociación inversa entre la presencia del GBV-C y los valores de carga viral de } \\
\text { VIH, pero no relación significativa con mayores recuentos de linfocitos CD4 }\end{array}$ & Brasil & Giret y cols 2011 \\
\hline Descriptivo & Pacientes & 102 & $\begin{array}{l}\text { No se observó una asociación fuerte entre la presencia de marcadores de } \\
\text { infección del GBV-C y los recuentos de linfocitos CD4 o carga viral }\end{array}$ & Brasil & Alves y cols 2012 \\
\hline
\end{tabular}

de caracterización genotípica del GBV-C en pacientes co-infectados con VIH, se ha reportado que el genotipo 2 es el más frecuente en esta población ${ }^{24}$. En Latinoamérica, estudios de prevalencia del GBV-C en pacientes infectados con VIH muestran frecuencias variables. En Argentina se encontró $13,51 \%$ de co-infección GBV-C/ VIH en una cohorte de pacientes hemofílicos; además se detectó una mayor prevalencia de infección del GBV-C en pacientes con mejor pronóstico clínico y menor riesgo de progresión a SIDA ${ }^{25}$. En Brasil, dos estudios realizados en cohortes diferentes de pacientes infectados por el VIH revelaron una co-infección de 23 y $30 \%$, encontrándose en ambos estudios el genotipo $2 \mathrm{~b}$ del GBV-C como el más frecuente ${ }^{26,27}$. Adicionalmente la co-infección con este genotipo se asoció con menor carga viral, mayores recuentos de $\mathrm{CD} 4+$ y mejor respuesta inmunológica en pacientes con terapia anti-retroviral en curso $^{26}$.

Debido a que el GBV-C y el VIH se replican en la misma célula blanco, recientes investigaciones se han enfocado en determinar la interacción que existe entre estos virus en el contexto de la co-infección. Diversos autores plantean que el GBV-C es capaz de inhibir la replicación del VIH-1, y por lo tanto, mejora el pronóstico clínico de estos pacientes y la progresión a $\mathrm{SIDA}^{28}$. Al comparar poblaciones de pacientes infectados por el VIH, con y sin viremia detectable para el GBV-C, se han encontrado mayores recuentos de CD4 y una mayor supervivencia en los que se evidencia presencia del genoma de GBV-
$\mathrm{C}^{29}$. Así mismo, al comparar pacientes con replicación del GBV-C (viremia detectable) y pacientes con anti-E2 pero sin viremia detectable, se observa que aquellos con replicación activa del GBV-C son quienes presentan mejor pronóstico. Por otro lado, estudios in vitro muestran la inhibición de la replicación tanto de cepas R5 como $\mathrm{X} 4$ por parte del GBV-C, utilizando como marcador los niveles del antígeno $\mathrm{p} 24^{29}$.

Aunque es cuestión de debate, existen estudios sero-epidemiológicos y de cohorte con resultados contradictorios, en los que se concluye que la co-infección no se asocia con beneficio en el desenlace clínico de los pacientes $^{4,30,31}$. Es el caso de un estudio de cohorte que involucró 18 mujeres de origen africano infectadas con el VIH-1 o el VIH-2 y co-infectadas por el GBV-C. En este trabajo no se observaron diferencias en la carga viral de VIH o en los recuentos de CD4, ni en la mortalidad de las mujeres co-infectadas, en comparación con las no co-infectadas. Sin embargo, es de anotar el bajo número de mujeres seguidas en el análisis lo que limita la posibilidad de resultados concluyentes ${ }^{32}$. Otros estudios en diferentes cohortes observan resultados similares, reportando ausencia de relación entre el GBV-C y la supervivencia, el pronóstico (falla virológica o inmunológica), o la respuesta a la terapia HAART ${ }^{30,31}$. Recientemente en Brasil, se evaluó la carga viral y el recuento de linfocitos CD4+ y CD8+ en pacientes GBV-C/VIH co-infectados versus no co-infectados; entre la cohorte de 233 pacientes no se 
observó diferencia estadísticamente significativa ${ }^{27}$. Sin embargo, otro trabajo realizado en Sao Paulo, publicado en 2012, concluyó la existencia de un impacto positivo sobre la carga viral del VIH en pacientes co-infectados ${ }^{33}$. Lo anterior sugiere que podría no existir una asociación directa entre la infección por el GBV-C y el pronóstico de los pacientes infectados con el VIH-1. Dado que estos resultados contrastan con lo obtenido en otros estudios de cohorte, y con los hallazgos in vitro, se hace necesario el desarrollo de trabajos adicionales, con diseños metodológicos que permitan concluir el significado clínico de la co-infección GBV-C/VIH-1, y determinar los factores implicados en la interacción entre estos dos virus en el contexto de co-infección.

\section{Inhibición de la replicación del VIH-1}

\section{Inmunomodulación por el GBV-C}

En un número considerable de trabajos in vitro se concluye que la infección por virus de la familia Flaviviridae involucra la modulación de la respuesta inmune; en el caso del GBV-C, se ha observado aumento la expresión de quimioquinas que se unen a los co-receptores CCR5 y CXCR4. La expresión de factores solubles es significativamente más alta en pacientes co-infectados GBV-C/ $\mathrm{VIH}$, en comparación con infección por $\mathrm{VIH}^{34}$. Entre las hipótesis propuestas para explicar el efecto del GBV-C sobre la infección por el VIH, se ha sugerido que el mecanismo podría estar dado por inhibición competitiva de las quimioquinas RANTES, MIP1- $\alpha$, MIP1- $\beta$ y SDF$1 \alpha$ sobre el VIH y su interacción con CCR5 y CXCR4. También se demostró que la co-infección GBV-C/VIH-1 en individuos con enfermedad avanzada se asocia con una baja expresión de los co-receptores CCR5 y CXCR4 en la membrana de linfocitos T CD $4+{ }^{37}$.

Análisis in vitro describen que estas quimioquinas son capaces de inhibir la infección por el $\mathrm{VIH}^{4,35}$, proponiéndose dos modelos para este efecto (Figura 3A). En el primero, las quimioquinas se unen al dominio de unión del co-receptor (CXCR4 o CCR5) que interactúa con gp120, causando un impedimento estérico que afecta la entrada del VIH a las células blanco. El otro modelo sugiere que existe una internalización del co-receptor inducida por las quimioquinas (por ejemplo: SDF-1), disminuyendo la expresión de estas moléculas en la superficie de las células y por lo tanto, afectando el reconocimiento de las células blanco por parte de las glicoproteínas de la envoltura viral ${ }^{36}$. Durante la infección por GBV-C se ha descrito una disminución en la expresión de la molécula CCR5, que parece estar mediada por la interacción de la proteína E2, la cual induce una acumulación intracelular del co-receptor CCR5, según se demostró in vitro en linfocitos estimulados con la proteína E2 del GBV-C. ${ }^{37}$ Adicionalmente, análisis recientes indican que el GBV-C

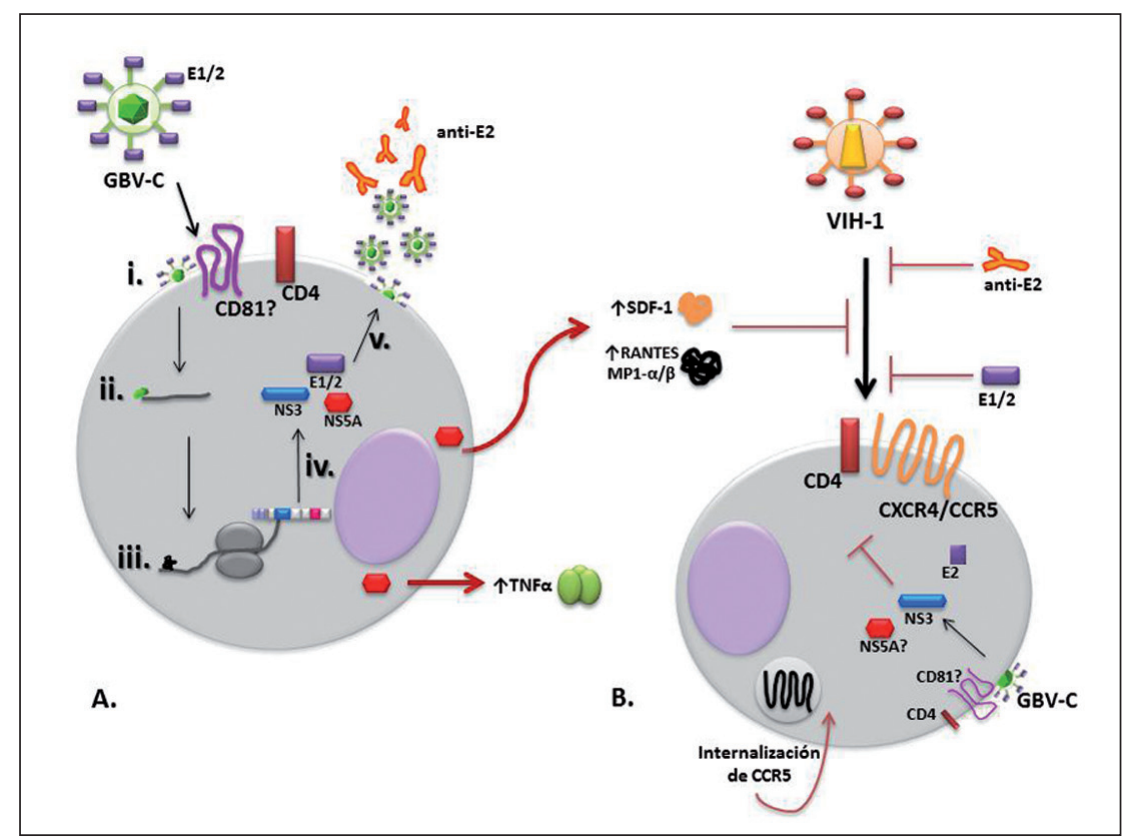

Figura 3. Efectos de la interacciónentre el GBV-C y el VIH-1. En el gráfico se muestran los mecanismos propuestos de inhibición de $\mathrm{VIH}-1$ durante el estado de co-infección. (A) Se observan algunos de los pasos esenciales del ciclo replicativo del GBV-C. i Entrada del virus a su célula blanco mediada por la interacción entre las glicoproteínas de la envoltura viral (E1/2)y el receptor celular; la molécula CD81 se ha propuesto como posible receptor. ii Desnudamiento del ARN genómico en el citoplasma. iii Traducción del ARN genómico dependiente del IRES ubicado en 5'NTR, dando lugar a la poliproteína precursora. iv Procesamiento y maduración de las proteínas virales, mediado por proteasas celulares y NS3/4A; para las proteínas del GBV-C resaltadas en el esquema (E1/2, NS3, NS5A) se ha reportado actividad inhibitoria in vitro contra el VIH-1. Las proteínas no estructurales del GBV-C participan en la síntesis de nuevas copias del ARN, a través de la producción secuencial del antigenoma y el genoma viral por NS5B. v Con base en el modelo del VHC, una vez generadas nuevas copias del genoma las partículas virales se ensamblan y salen de la célula por gemación. Según estudios in vitro, durante el ciclo replicativo del GBV-C la célula blanco aumentará la expresión las quimioquinas SDF-1, RANTES, $\mathrm{MP} 1 \alpha / \beta$ y la producción de citoquinas del perfil Th1, principalmente el factor de necrosis tumoralalfa (FNT $\alpha$ ) debido al estimulo mediado por la proteína NS5A como se indica en el gráfico. Después de un periodo variable de establecida la infección, se producen anticuerpos neutralizantes contra las glicoproteínas de envoltura (Anti-E2). (B) Se esquematiza el efecto derivado de la replicación del GBV-C sobre el VIH-1; laproducción aumentada de las quimioquinas SDF-1, RANTES y MP1- $\alpha / \beta$ estaría bloqueando de manera competitiva la interacción de $\mathrm{VIH}-1$ con los respectivos co-receptores y/o induciendo su internalización, y por lo tanto afectando los pasos de adhesión y penetración en la célula blanco. Así mismo, evidencias experimentales indican que las glicoproteínas de envoltura del GBV-C (E1/2) y/o anticuerpos anti-E2 también tendrían la capacidad de inhibir la unión de VIH-1 a su receptor y/o la fusión de membranas. Estudios recientes proponen que la glicoproteína E2 y la proteasa NS3 afectan pasos post-entrada. Adicionalmente un mecanismo directo intracelular ha sido propuesto para NS5A pero no ha sido demostrado experimentalmente.

tiene además la capacidad de regular a nivel transcripcional la expresión del co-receptor CXCR4, reportándose disminución del mARN y de la molécula en membrana en células Jurkat que expresan la proteína NS5A del GBV-C. Existen también reportes acerca de la inhibición de la replicación del VIH en células CD4+ y de la disminución de la expresión de este receptor por parte de algunos virus pertenecientes a la familia Flaviviridae, como los virus de dengue, fiebre amarilla, hepatitis $\mathrm{C}$ y virus del oeste del Nilo ${ }^{38}$. Aunque no está totalmente dilucidado el mecanismo mediante el cual el GBV-C inhibe la replicación 
del VIH, hasta el momento existen evidencias que tanto la glicoproteína E2 de la envoltura viral como la proteína NS5A podrían estar involucradas, ya que la co-expresión de estas proteínas inhibe la replicación del VIH in vitro.

\section{Glicoproteína E2}

La proteína E2 del GBV-C tiene un tamaño aproximado de 387 aminoácidos y un peso de $41,8 \mathrm{kDa}$, formando un heterodímero con la proteína E1 para conformar la envoltura viral ${ }^{18}$. Esta glicoproteína posee una gran similitud con la proteína E2 del VHC, en el extremo C-terminal presenta regiones hidrofóbicas que conforman el dominio transmembrana (TM); sin embargo existen diferencias en el número de sitios de glicosilación, y en que la proteína E2 del GBV-C no presenta regiones hipervariables, como sí es el caso de $\mathrm{VHC}^{39}$. A la fecha se considera que E2 es la proteína encargada de la interacción entre GBV-C y el receptor celular para la entrada a la célula blanco. In vitro se ha evidenciado que E2 es capaz de interactuar con diferentes líneas celulares Molt-4, HeLa, Jurkat, HEK293 y con la línea de fibroblastos 3T3, lo que evidencia una amplia distribución del receptor celular utilizado por el GBV-C. De manera similar a lo descrito para VHC, E2 puede unirse a diferentes tipos celulares; no obstante, la penetración del virus a la célula no es posible sin un receptor adicional ${ }^{18}$.

La molécula CD81 interviene en la adhesión mediada por la proteína E2 del VHC a la célula blanco y ha sido propuesta como receptor para el GBV-C; sin embargo, no este aspecto no está completamente dilucidado (Figura 3A). La interacción GBV-C E2-CD81 explicaría en parte el mecanismo de inhibición de la entrada del VIH, según se demostró in vitro, en linfocitos que fueron estimulados con E2 del GBV-C, donde se observó una reducción en la expresión del co-receptor CCR5; adicionalmente se demostró que esta reducción fue dependiente de la interacción E2-CD81 ${ }^{40}$. Existen algunos hallazgos in vitro que sugieren que E2 GBV-C podría ser ligando de moléculas distintas a CD81, ya que al evaluar la interacción de E2 con células Daudi, las cuales se caracterizan por expresar altos niveles de CD81, no se observó adhesión significativa de la glicoproteína a la membrana celular; adicionalmente, la unión de E2 a sus células blanco no es bloqueada competitivamente por moléculas de CD81 solubles ${ }^{41}$. En conjunto estos resultados sugieren que la unión E2-CD81 no es específica, por lo que deberán continuar los esfuerzos para tratar de esclarecer este aspecto de la replicación del GBV-C.

A pesar de que no está identificado el receptor utilizado por el GBV-C, estudios de Jung y cols., demostraron que la incubación de células mononucleares de sangre periférica (PBMCs) con la glicoproteína E2 del GBV-C, en su forma nativa y/o truncada $\left(\mathrm{E} 2_{340}-\mathrm{Fc}\right)$, inhiben la infección por el VIH; efecto que se revierte, al incubar las células con anticuerpos anti-E2. Con base en estos resultados, y con el fin de determinar el mecanismo de inhibición, se han diseñado pseudopartículas de VIH (con la glicoproteína del VSG) capaces de ingresar a la célula mediante endocitosis, encontrando ausencia de inhibición, lo que sugiere que E2 interviene específicamente en el paso de adhesión del $\mathrm{VIH}^{42,43}$. Otros estudios más recientes sugieren la posibilidad de que péptidos derivados de la glicoproteína E2 del GBV-C tendrían la capacidad de inhibir la unión al receptor y/o la fusión de VIH vía interacción con la partícula viral, o incluso realizar la inhibición en pasos tempranos pos-entrada ${ }^{43,44}$ (Figura 3B); Koedel y cols., utilizaron 32 péptidos sintéticos derivados de E2, que al ser adicionados a cultivos celulares antes de la infección con VIH (pseudopartículas virales), inhibieron el paso de entrada. Específicamente identificaron que las porciones entre los residuos 45 a 64 (péptido P6-2) y 37 a 64 (péptido P4762) presentaban la actividad más alta para afectar el ciclo replicativo de VIH; al hacer el análisis más detallado, la inhibición en el modelo utilizado involucraba un mecanismo no reportado previamente de interacción directa con las glicoproteínas de $\mathrm{VIH}^{44}$. En cuanto a la inhibición de VIH-1 en pasos post-entrada, Xiang y cols., utilizando un modelo de expresión constitutiva de E2 en células Jurkat demostraron disminución en la síntesis de p24. Estos autores encontraron que la actividad inhibitoria fue asociada a 17 residuos de E2 (276-292aa), distinto a lo reportado anteriormente por Koedel y cols. Al tratar de evaluar la actividad de E2, utilizando un péptido sintético compuesto por estos $17 \mathrm{aa}$, la actividad inhibitoria sobre VIH no fue observada, siendo re-establecida sólo cuando se aseguraba la entrada del péptido al fusionarlo con el dominio de transducción de la proteína viral TAT, indicando que E2 tendría un mecanismo adicional de inhibición de VIH dependiente de su ingreso a la célula (paso post-entrada) ${ }^{43}$.

De otra parte, se ha observado actividad neutralizante anti-VIH con anticuerpos anti-E2 del GBV-C (anti-GB/ E2). Cuando células MT-2 son incubadas con anti-GB/ E2 purificados a partir de sueros de individuos naturalmente infectados, o de suero de conejos inmunizados con péptidos truncados de la glicoproteína E2, se evidencia una reducción significativa en la producción de antígeno p24, indicando que los anticuerpos anti-E2 tienen la capacidad de inhibir la entrada del VIH a su célula blanco ${ }^{45}$; en principio, esto también se relacionaría con la mayor sobrevida descrita en algunos individuos con infección por VIH que no presentan viremia para el GBV-C pero sí anticuerpos anti-GB/E2 ${ }^{46}$ (Figura 3B).

\section{Proteína NS5A}

La proteína no estructural 5A del GBV-C tiene un tamaño aproximado de 414 aminoácidos; es una fosfoproteína descrita en dos formas: la basal (p56) y la forma hiperfos- 
forilada (p58). NS5A es reconocida como una proteína con capacidad para interactuar con múltiples blancos celulares. Teniendo en cuenta los estudios realizados para el VHC, NS5A se localiza en retículo endoplásmico gracias a que en su extremo amino-terminal se encuentra una hélice anfipática de interacción a membrana, siendo necesaria para la replicación viral ${ }^{47,48}$. Se han caracterizado tres dominios principales; el dominio I localizado en el extremo amino-terminal que presenta motivos de zinc para unión a ácidos nucleicos, mientras los dominios II y III contienen los sitios de hiperfosforilación y fosforilación basal, respectivamente ${ }^{49}$.

En 2006 Xiang y cols., demostraron que la expresión transitoria de la proteína NS5A de los genotipos 1, 2, 3 y 5 del GBV-C en células Jurkat inhibe significativamente la replicación del VIH, lo cual fue estimado según los niveles del antígeno p24 en los sobrenadantes de cultivo. Adicionalmente, se reportó una disminución en la expresión de CXCR4 y un incremento en la producción de su ligando SDF-1, con respecto al control (Figura 3B). Análisis más detallados, han demostrado que la región de la proteína correspondiente a los residuos aminoacídicos del 152 a 236 de la proteína son suficientes para inhibir la replicación del VIH. Adicionalmente, se reportó inhibición cuando se expresó la región con los aminoácidos entre 152-181, región en la que se encuentran cuatro sitios de fosforilación, los cuales serían importantes para la actividad inmunomoduladora, lo que sugiere la existencia de mecanismos adicionales que median la inhibición del $\mathrm{VIH}^{50,51}$. Estos resultados sugieren que todos los genotipos del GBV-C son capaces de inhibir la replicación del VIH, y que el posible mecanismo se relaciona con la modulación en la producción de la quimioquina SDF-1, quimioquina con potencial para competir por el co-receptor CXCR4, para lo cual se ha propuesto que es capaz de afectar pasos post-entrada, similar a lo reportado para MIP1- $\alpha^{52}$. En concordancia con el mecanismo inmunomodulador, un reporte recientemente publicado por Rydze y cols., en 2012, aporta evidencias de que la infección por GBV-C o específicamente la expresión de la proteína NS5A, polarizan la respuesta inmune hacia el perfil Th1, disminuyendo la expresión de citoquinas Th2 (interleuquinas 4, 5, 10 y 13) en PBMCs, lo que explicaría en parte el efecto benéfico encontrado en individuos co-infectados ${ }^{53}$. Es probable que el mecanismo de NS5A no esté solo relacionado con la modulación de las quimioquinas y la polarización del perfil de citoquinas, por lo que es necesario investigar la existencia de un efecto directo sobre el ciclo replicativo del VIH.

\section{Otros mecanismos propuestos en la inhibición del VIH mediada por el GBV-C}

Recientemente, otros mecanismos adicionales aunque menos estudiados han sido propuestos para explicar la inhibición del VIH mediada por el GBV-C. Existen evidencias in vitro de que proteínas virales diferentes a E2 y NS5A podrían tener el potencial para afectar el ciclo replicativo del $\mathrm{VIH}^{54}$, como es el caso de las proteínas E1 y NS3 del GBV-C (Figura 3B). Basado en el estudio de secuencias y de homología estructural, se ha predicho que el extremo carboxilo-terminal de la glicoproteína E1 presenta un dominio hidrofóbico alfa-hélice que le permite anclarse al retículo endoplasmático. La proteína tiene un tamaño de 188 aminoácidos y un peso aproximado de $20,7 \mathrm{kDa}$, con un solo sitio de glicosilación ${ }^{55}$. Estudios en membranas, específicamente vesículas fosfolipídicas unilamelares, y péptidos sintéticos derivados de la proteína E1 del GBV-C, demostraron la capacidad que tienen diferentes porciones del extremo amino-terminal de E1, principalmente los residuos 64 a 81, para afectar hasta en $50 \%$ la fusión de membrana mediada por la proteína de envoltura gp41 del VIH; alterándose el ciclo replicativo del VIH al limitar su entrada a la células blanco ${ }^{56}$. Más recientemente, se identificó un nuevo mecanismo de inhibición de la replicación de VIH mediado por NS3, la serina-proteasa del GBV-C. En este trabajo publicado en 2012 por George SL y cols., se observó como la cotransfección del clon infeccioso de VIH pNL4-3 y un constructo que expresaba GBV-C/NS3, reducía la generación de viriones en la línea celular Jurkat, sin disminuir la expresión de receptores celulares, demostrando un mecanismo independiente de la entrada. En este mismo trabajo los autores encontraron inhibición aún más marcada si la co-transfección era realizada simultáneamente con constructos que codificaban para las proteínas no estructurales NS4A y NS4B del GBV-C, constituyéndose en un nuevo mecanismo antiviral en este modelo ${ }^{57}$.

\section{Conclusiones}

La infección por el GBV-C es característicamente frecuente en pacientes infectados con el VIH, debido a que comparten las mismas rutas de transmisión. Aunque los trabajos epidemiológicos revisados para el presente manuscrito muestran que la co-infección GBV-C/VIH tiene un efecto en el desenlace clínico, mejorando la sobrevida y retrasando el progreso a SIDA en los pacientes, la divergencia de algunos estudios que no describen algún efecto benéfico hace necesario realizar investigaciones tendientes a esclarecer la importancia clínica de esta co-infección, en los cuales se puedan explorar diferentes variables como la estadificación del paciente VIH, la medición de citoquinas de los perfiles Th1/Th2, la determinación del momento de infección por el GBV-C en relación con el tiempo de la seroconversión para VIH, la evaluación de la cargas viral de GBV en el tiempo de estudio, la titulación de anticuerpos anti-E2 y la identificación de los genotipos presentes en la co-infección, entre otros. 
Según los estudios in vitro realizados hasta la fecha, las proteínas E2 y NS5A del GBV-C estarían involucradas en la inhibición de la replicación del VIH durante la co-infección, mediante un mecanismo de inmunomodulación de los co-receptores CXCR4 y CCR5, y de las quimioquinas RANTES, MP1- $\alpha$, MP1- $\beta$, y SDF-1. Otros mecanismos como la polarización de la expresión de citoquinas a un perfil Th1 por NS5A, así como el bloqueo de las etapas de interacción de las glicoproteínas de VIH con su receptor celular y la fusión de membranas por E2, también han sido sugeridos para explicar el efecto del GBV-C en la replicación del VIH-1. Recientemente, se ha propuesto que las proteínas E1 y NS3 del GBV-C pueden tener un efecto en la interacción con el VIH-1; por ejemplo, mediante la actividad serina-proteasa de NS3/4A. A pesar de que existe una mayor entendimiento sobre el efecto inhibitorio del GBV-C sobre la replicación del VIH-1, es necesario continuar esclareciendo los mecanismos directos e indirectos, incluida la posible interacción con proteínas celulares, así como el conocimiento actual sobre las proteínas del GBV-C, ya que mucha de la información disponible se basa mayormente en análisis de predicción y comparación con VHC. Los estudios aquí descritos y el desarrollo de investigaciones adicionales permitirán proponer en el futuro nuevas estrategias terapéuticas para el tratamiento de la infección por VIH.
Agradecimientos. Los autores agradecen a la dirección de investigación del Instituto Tecnológico Metropolitano (ITM), Institución Universitaria Adscrita a la Alcaldía de Medellín (ITM Grant: P10243).

\section{Resumen}

La infección por el virus de la inmunodeficiencia humana (VIH) continúa siendo uno de los principales problemas en salud pública; se estima que existen actualmente más de 33 millones de personas infectadas en el mundo. El VIH y el virus GB tipo C (GBV-C) comparten la misma vía de transmisión, por lo que es frecuente encontrar individuos co-infectados. Estudios recientes han descrito un efecto inhibitorio asociado a disminución en la carga viral de VIH, altos recuentos de CD4 y mayor tiempo de sobrevida en pacientes co-infectados, resultando en un mejor pronóstico y menor progreso a SIDA; adicionalmente, estudios in vitro indican que las proteínas virales E1, E2, NS3 y NS5A del GBV-C estarían implicadas en la inhibición del VIH-1. En el presente artículo se revisan los principales aspectos de la co-infección, y se describen los mecanismos propuestos para la inhibición de la replicación del VIH-1 mediada por las proteínas virales del GBV-C.

\section{Referencias bibliográficas}

1.- Stapleton J T, Foung S, Muerhoff A S, Bukh J, Simmonds P. The GB viruses: a review and proposed classification of GBV-A, GBV-C (HGV), and GBV-D in genus Pegivirus within the Familie Flaviviridae. J Gen Virol 2011; 92 (Pt 2): 233-46. doi: 10.1099/vir.0.027490-0. Epub 2010 Nov 17.

2.- Muerhoff A S, Leary T P, Simons J N, Pilot-Matias T J, Dawson G J, Erker J C, et al. Genomic organization of GB viruses A and B: two new members of the Flaviviridae associated with GB agent hepatitis. J Virol 1995; 69(9): 5621-30.

3.- Simons J N, Pilot-Matias T J, Leary T P, Dawson G J, Desai S M, Schlauder G G, et al. Identification of two flavivirus-like genomes in the GB hepatitis agent. Proc Natl Acad Sci USA 1995; 92 (8): 3401-5.

4.- Berzsenyi M D, Bowden D S, Roberts S K. GB virus C: insights into co-infection. J Clin Virol 2005; 33 (4): 257-66.

5.- Cortés-Mancera F, Arroyave J. Estudio del virus GB tipo-C en Colombia. Capítulo de memorias Técnicas Celulares y Moleculares. II Simposio. ISBN: 978-958-8743-12-7 ed: Instituto Tecnológico Metropolitano, 2012:71-94. http:// fondoeditorial.itm.edu.co/Libroselectronicos/ SimposioTCM/index.html.
6.- González-Pérez M A, Norder H, Bergström A, Lopéz E, Visoná K A, Magnius L O, et al. High prevalence of GB virus $C$ strains genetically related to strains with Asian origin in Nicaraguan hemophiliacs. J Med Virol 1997; 52 (2): 149-55.

7.- Reshetnyak V I, Karlovich T I, Ilchenko L U. Hepatitis G virus. World J Gastroenterol 2008; 14 (30): 4725-34.

8.- Bortolin M T, Zanussi S, Tedeschi R, Pratesi C, D'Andrea M, Bidoli E, et al. Evaluation of three molecular biology-based assays for the detection of $\mathrm{GB}$ virus $\mathrm{C} /$ hepatitis $\mathrm{G}$ virus in clinical specimens. Intervirology. 2004; 47(6): 314-20.

9.- Gómara M J, Fernández L, Pérez T, Ercilla G, Haro I. Assessment of synthetic chimeric multiple antigenic peptides for diagnosis of GB virus $C$ infection. Analytical Biochem 2010; 396 (1): 51-8.

10.- Lara C, Halasz R, Sönnerborg A, Sällberg M. Detection of hepatitis $\mathrm{G}$ virus RNA in persons with and without known risk factors for bloodborne viral infections in Sweden and Honduras. J Clin Microbiol 1998; 36 (1): 255-7.

11.- George S L, Varmaz D, Stapleton J T. Brief report $\mathrm{GB}$ virus $\mathrm{C}$ replicates in primary $\mathrm{T}$ and $\mathrm{B}$ lymphocytes. J Infect Dis. 2006; 193: 451-4.

12.- Bartolome J, Fogeda M, Lo J M, Arocena C, Marti M A. Existence of distinct GB virus C/ hepatitis $\mathrm{G}$ virus variants with different tropism. J Virol 2000; 74 (17): 7936-42.

13.- Krajden M, Yu A, Braybrook H, Lai A S, Mak A, Chow R, et al. GBV-C/hepatitis G virus infection and non-Hodgkin lymphoma: a case control study. Inter J Cancer 2010; 126 (12): 2885-92.

14.- Brown T, Bao L, Raftery AE, Salomon J A, Baggaley R F, Stover J, et al. Modelling HIV epidemics in the antiretroviral era: the UNAIDS estimation and projection package 2009. Sex Transm Infec 2010; 86 (2): 3-10.

15.- Nielsen M H, Pedersen F S, Kjems J. Molecular strategies to inhibit HIV-1 replication. Retrovirology 2005; 20: 1-20.

16.- Briggs J A G, Kräusslich H-G. The molecular architecture of HIV. J Mol Biol 2011; 410 (4): 491-500.

17.- Carter C A, Ehrlich L S. Cell biology of HIV-1 infection of macrophages. Annu Rev Microbiol 2008; 62: 425-43.

18.- Mortier A, Damme J V, Proost P. Regulation of chemokine activity by posttranslational modification. Pharmacol Ther 2008; 120 (2): 197-217.

19.- Cavarelli M, Scarlatti G. Phenotype variation in human immunodeficiency virus type 1 transmission and disease progression. Disease Markers 2009; 27: 121-36.

20.- Coiras M, López-Huertas M R, Pérez-Olmeda 
M, Alcamí J. Understanding HIV-1 latency provides clues for the eradication of long-term reservoirs. Nat Rev Microbiol 2009; 7 (11): 798-812.

21.- Buonaguro L, Tornesello M L, Buonaguro F M. Human immunodeficiency virus type 1 subtype distribution in the worldwide epidemic: pathogenetic and therapeutic implications. J Virol 2007; 81(19): 10209-19.

22.- Compston L I, Li C, Sarkodie F, Owusu-Ofori S, Opare-Sem O, Allain J P. Prevalence of persistent and latent viruses in untreated patients infected with HIV-1 from Ghana, West Africa. J Med Virol 2009; 1868: 1860-8.

23.- Hekmat S, Mohraz M, Vahabpour R, Jam S, Bahramali G, Banifazl M, et al. Frequency and genotype of $\mathrm{GB}$ virus $\mathrm{C}$ among Iranian patients infected with HIV. J Med Virol 2008; 80: 1941-6.

24.- Muerhoff A S, Tillmann H L, Manns M P, Dawson G J, Desai S M. GB Virus C genotype determination in GB virus-C/HIV co-infected individuals. J Med Virol. 2003; 70: 141-9.

25.- Massud I, Corti M, de Tezanos Pinto M, Pérez Bianco R, Picchio G, Baré P. Prevalence of hepatitis $\mathrm{G}$ virus infection in a cohort of hemophilic HIV positive patients. Med 2002; 62: 173-5.

26.- Alcalde R, Nishiya A, Casseb J, Inocêncio L, Fonseca L A, Duarte A J. Prevalence and distribution of the GBV-C/HGV among HIV-1infected patients under anti-retroviral therapy. Virus Res 2010; 151 (2): 148-52.

27.- Giret M T, Miraglia J L, Sucupira M C, Nishiya A, Levi J E, Díaz R S, et al. Prevalence, incidence density, and genotype distribution of GB virus $C$ infection in a cohort of recently HIV-1-infected subjects in Sao Paulo, Brazil. PloS one 2011; 6 (4): e18407.

28.- Tillmann H L, Heiken H, Knapik-Botor A, Heringlake S, Ockenga J, Wilber J C, et al. Infection with GB virus $\mathrm{C}$ and reduced mortality among HIV-infected patients. N Engl J Med. 2001; 345 (10): 715-24.

29.- Xiang J, Wünschmann S, Diekema D J, Klinzman D, Patrick K D, George S L, et al. Effect of coinfection with $\mathrm{GB}$ virus $\mathrm{C}$ on survival among patients with HIV infection. New Engl J Med 2001; 345 (10): 707-14.

30.- Björkman P, Flamholc L, Nauclér A, Molnegren V, Wallmark E, Widell A. GB virus $\mathrm{C}$ during the natural course of HIV-1 infection: viremia at diagnosis does not predict mortality. AIDS 2004; 18( 6): 877-86.

31.- van der Bij A K, Prins M, Geskus R G. Response to ' $\mathrm{GB}$ virus $\mathrm{C}$ during the natural course of HIV-1 infection: viremia at diagnosis does not predict mortality. AIDS 2004; 18 (17): 2344-5; author reply: 2345-6.

32.- Kaye S, Howard M, Alabi A, Hansmann A, Whittle H, Schim van der Loeff M. No observed effect of $\mathrm{GB}$ virus $\mathrm{C}$ coinfection on disease progression in a cohort of African woman infected with HIV-1 or HIV-2. Clin Infect Dis. 2005; 40 (6): 876-8.

33.- Alves-Sousa V K, Komninakis S C, BaggioZappia G L, Barbosa A J, Mantovani N P, Díaz R S, et al. Evaluation of GB virus C/ hepatitis $\mathrm{G}$ viral load among HIV type 1coinfected patients in São Paulo, Brazil. AIDS Res Hum Retroviruses 2012. doi:10.1089/ aid.2011.0212.

34.- Xiang J, George S L, Wünschmann S, Chang Q, Klinzman D, Stapleton J T. Inhibition of HIV-1 replication by $\mathrm{GB}$ virus $\mathrm{C}$ infection through increases in RANTES, MIP-1alpha, MIP-1beta, and SDF-1. Lancet 2004; 363 (9426): 2040-6.

35.- Cocchi F, DeVico A L, Garzino-Demo A, Arya S K, Gallo R C, Lusso P. Identification of RANTES, MIP-1 alpha, and MIP-1 beta as the major HIV-suppressive factors produced by CD8+ T cells. Science 1995; 270 (5243): 1811-5.

36.- Simon J H, Stumbles P, Signoret N, Somoza C, Puklavec M, Sattentau QJ, et al. Role of CD4 epitopes outside the gp120-binding site during entry of human immunodeficiency virus type 1 . J Virol 1997; 71 (2): 1476-84.

37.- Schwarze-Zander C, Neibecker M, Othman S, Tural C, Clotet B, Blackard J T, et al. GB virus $\mathrm{C}$ coinfection in advanced HIV type-1 disease is associated with low CCR5 and CXCR4 surface expression on CD4(+) T-cells. Antivir Ther 2010; 15 (5): 745-52.

38.- Xiang J, McLinden J H, Rydze R A, Chang Q, Kaufman T M, Klinzman D, et al. Viruses within the Flaviviridae decrease CD4 expression and inhibit HIV replication in human CD4+ cells. J Immunol 2009; 183(12): 7860-9.

39.- Moradpour D, Penin F, Rice C M. Replication of hepatitis C virus. Nature Rev. 2007; 5: 453-63.

40.- Nattermann J, Nischalke H, Kupfer B. Regulation of CC chemokine receptor 5 in hepatitis G virus infection. AIDS 2003; 17: 1457-62.

41.- Kaufman T M, McLinden J H, Xiang J, Engel A M, Stapleton J T. The GBV-C envelope glycoprotein E2 does not interact specifically with CD81. AIDS 2007; 21(8): 1045-8.

42.- Jung S, Eichenmüller M, Donhauser N, Neipel F, Engel A M, Hess G, et al. HIV entry inhibition by the envelope 2 glycoprotein of GB virus C. AIDS 2007; 21 (5): 645-7.

43.- Xiang J, McLinden J H, Kaufman T M, Mohr E L, Bhattarai N, Chang Q, et al. Characterization of a peptide domain within the GB virus $C$ envelope glycoprotein (E2) that inhibits HIV replication. Virology 2012; 430 (1): 53-62.

44.- Koedel Y, Eissmann K, Wend H, Fleckenstein B, Reil H. peptides derived from a distinct region of GB virus $\mathrm{C}$ glycoprotein $\mathrm{E} 2$ mediate strain-specific HIV-1 entry inhibition. J Virol 2011; 85 (14): 7037-47.

45.- Mohr E L, Xiang J, McLinden J H,
Kaufman T M, Chang Q, Montefiori D C, et al. GB virus type $\mathrm{C}$ envelope protein $\mathrm{E} 2$ elicits antibodies that react with a cellular antigen on HIV-1 particles and neutralize diverse HIV-1 isolates. J Immunol 2012: 4496-505.

46.- Tillmann H L, Manns M P. GB virus-C infection in patients infected with the human immunodeficiency virus. Antivir Res 2001; 52 (2): 83-90.

47.- Macdonald A, Harris M. Hepatitis C virus NS5A: tales of a promiscuous protein. J Gen Virol 2004; 85 (Pt 9): 2485-502.

48.- Brass V, Pal Z, Sapay N, Deléage G, Blum H E, Penin F, et al. Conserved determinants for membrane association of nonstructural protein $5 \mathrm{~A}$ from hepatitis $\mathrm{C}$ virus and related viruses. J Virol 2007; 81 (6): 2745-57.

49.- Huang Y, Staschke K, Francesco R D, Tan S. Phosphorylation of hepatitis C virus NS5A nonstructural protein: A new paradigm for phosphorylation-dependent viral RNA replication? Virology 2007; 364: 1-9.

50.- Xiang J, Mclinden J H, Chang Q, Kaufman T M, Stapleton J T. An 85-aa segment of the GB virus type C NS5A phosphoprotein inhibits HIV-1 replication in CD4 Jurkat T cells Proc Natl Acad Sci USA 2006; 103 (42): 1-6.

51.- Chang Q, Mclinden J H, Stapleton J T, Sathar M A. Expression of GB virus C NS5A protein from fragment inhibit human immunodeficiency virus type 1 replication in a CD4 + T-lymphocyte cell line. J Gen Virol 2007; 88: 3341-6.

52.- Amella C-A, Sherry B, Shepp D H, Schmidtmayerova H. Macrophage inflammatory protein 1alpha inhibits postentry steps of human immunodeficiency virus type 1 infection via suppression of intracellular cyclic AMP. J Virol 2005; 79 (9): 5625-31.

53.- Rydze R T, Xiang J, Mclinden J H. GB Virus type $\mathrm{C}$ infection polarizes T-cell cytokine gene expression toward a Th1 cytokine profile via NS5A protein expression. J Infect Dis 2012; 206: 69-72.

54.- Bhattarai N, Stapleton JT. GB virus C: the good boy virus? Trends Microbiol. 2012; 20 (3): 124-30.

55.- Mohr E L, Stapleton J T. GB virus type C interactions with HIV: the role of envelope glycoproteins. J Viral Hepat 2009; 16(11): 757-68.

56.- Sánchez-Martín M J, Busquets M A, Girona V, Haro I, Alsina MA. Effect of E1 (64-81) hepatitis $G$ peptide on the in vitro interaction of HIV-1 fusion peptide with membrane models. Biochim Biophys Acta 2011; 1808 (9): 2178-88.

57.- George SL, Varmaz D, Tavis JE, Chowdhury A. The GB virus $\mathrm{C}$ (GBV-C) NS3 serine protease inhibits HIV-1 replication in a CD4+ T lymphocyte cell line without decreasing HIV receptor expression. PloS one 2012; 7 (1): e30653. 